\title{
TRANSAÇÃO ADMINISTRATIVA TRIBUTÁRIA: UMA FORMA DE DESJUDICIALIZAÇÃO
}

\author{
Marcelo Romanelli Cezar Fernandes* \\ Carlos Victor Muzzi Filho**
}

\section{RESUMO}

O presente trabalho busca abordar a temática da transação tributária como alternativa à solução de conflitos entre o contribuinte e a Administração Tributária, visando a redução de processos executivos fiscais na esfera do Poder Judiciário. No decorrer do presente artigo, demonstrar-se-á que essa alternativa se faz necessária ante o notório congestionamento de processos na Justiça. Deste modo, serão examinadas as opções que o legislador adotou para solucionar tal questão, em especial, pela Lei no 13.988 , de 14 de abril de 2020.

Palavras-chave: Transação Tributária. Administração Pública. Contribuinte. Desjudicialização. Execução Fiscal.

\section{ADMINISTRATIVE TAX TRANSACTION: A FORM OF JUDICIALIZATION}

\begin{abstract}
This paper seeks to address the issue of tax transactions as an alternative to solving conflicts between the taxpayer and the Tax Administration, aiming to reduce tax enforcement proceedings in the sphere of the Judiciary. In the course of this article, it will be demonstrated that this alternative is necessary in the face of the notorious congestion of processes in Justice. Thus, the options that the legislator adopted to resolve this issue will be examined, in particular, by Law No. 13,988, of April 14, 2020.
\end{abstract}

Keywords: Tax Transaction. Public Administration. Taxpayer. Re-judicialization. Tax Enforcement.

\section{INTRODUÇÃO}

São inúmeros os dados que demonstram como o número de ações executivas fiscais, que tramitam no Poder Judiciário, vem aumentando anos após ano (CNJ, 2020, p.). Todavia, é de compreender que essa situação, quando analisada em um cenário mais amplo, classifica-se

\footnotetext{
* Mestrando em Direito pela Fundação Mineira de Educação e Cultura - FUMEC; Especialista em Direito Empresarial pela Faculdades Milton Campos. Advogado. Endereço eletrônico: romanelli@apaadv.com.br ** Doutor e Mestre em Direito Tributário pela Faculdade de Direito da Universidade Federal de Minas Gerais (UFMG); Especialista em Direito Público pelo IEC-PUC/MG. Professor do Programa de Pós-Graduação em Direito/Mestrado e do Curso de Direito da Fundação Mineira de Educação e Cultura - FUMEC. Advogado e Procurador do Estado de Minas Gerais. Endereço eletrônico: muzzi@ fumec.br
} 
como fator que compromete a entrega da prestação jurisdicional a partir do momento que se confunde o acesso à justiça com o acesso ao Judiciário. Tal contexto se deve muito ao fato de o sistema judicial brasileiro, excessivamente baseado no litígio e na sua resolução por sentença de mérito, não se preocupar em oferecer ao jurisdicionado a tutela jurisdicional efetiva, adequada e tempestiva, com ênfase na eficiência e qualidade do serviço público que deve ser prestado ao cidadão.

Nesse sentido, quando se volve a atenção, especificamente, para a ação de execução fiscal para cobrança de crédito tributário, essa situação se torna ainda mais preocupante. Segundo o relatório "Justiça em Números" publicado, em 2020, pelo Conselho Nacional de Justiça (CNJ, 2020), os processos executivos fiscais representam, aproximadamente, 39\% (trinta e nove por cento) do total de casos pendentes, correspondendo, ainda, a 70\% (setenta por cento) das execuções não concluídas pelo Poder Judiciário. O mesmo relatório destaca, ademais, o tempo de rotatividade do acervo desses processos, qual seja, em torno de 7 (sete) anos e 10 (dez) meses (CNJ, 2020). Vale dizer, mesmo que o Judiciário não recebessse mais novas execuções fiscais, ainda seria necessário todo esse tempo para liquidar o acervo existente.

No âmbito do Direito Tributário é mais difícil a possibilidade de soluções consensuais dada a ênfase nos princípios da tipicidade e da legalidade. A concepção mais restritiva da legalidade e da tipicidade enfatizam, ainda, suposta indisponibilidade do interesse público, de modo a consolidar uma cultura jruída (?) avessa às soluçoes consensuais, o que apenas agrava essa realidade em que se configura o excesso de litígios, sendo a Administração Pública, incluídas todas as suas esferas e níveis, a maior litigante do país, somando-se também o fato de ser incipiente as resoluções de conflitos fora do Poder Judiciário.

Muito embora já exista previsão no Código Tributário Nacional (CTN) da possibilidade da administração pública realizar transação com o contribuinte, faltava, no plano federal, a indispensável regulamentação legal, porque, segundo o CTN, cabe à lei estipular as condições para a sua realização (art. 171). De forma tardia, mas, em bom momento, foi editada a Medida Provisória $n^{\text {o }} 889$, de 24 de julho de 2019, que, posteriormente, foi convertida na Lei $\mathrm{n}^{\mathrm{o}} 13.988$, de 14 de abril de 2020, que regulamenta o art. 171 do CTN, disciplinando a transação tributária (apelidada de "Lei do Contribuinte Legal")).

É possível apontar que o legislador federal regulamentou a transação tributária federal tomando como base três pilares estruturantes do Código de Processo Civil de 2015 
(CPC/2015), a saber: a efetividade, a cooperação entre os sujeitos do processo e o mais importante, a pretensão de desjudicialização de conflitos.

Por meio da transação tributária, os três alicerces da legislação processual são concretizados na área tributária. É exatamente essa inovação legislativa o objeto do presente trabalho, que tem por objetivo demonstrar como a transação tributária federal pode ser utilizada para reduzir o número de processos no Poder Judiciário, e, principalmente, evitar a propositura de novas ações executivas fiscais.

Contextualizados esses apontamentos, ressalta-se que a primeira parte deste artigo será dedicada ao estudo da consensualidade no âmbito da administração pública. No segundo tópico, estudar-se-á o instituto da transação tributária, com a análise da Lei nº 13.988/2020, e, por fim, na terceira parte, será demonstrada a possibilidade da transação tributária como meio alternativo para a resolução de conflitos, contribuindo com a diminuição dos processos executivos fiscais, e, ainda, com o não ajuizamento de novas ações judiciais.

Utilizou-se, metodologicamente, o método hipotético-dedutivo jurídico. Foi realizada pesquisa bibliográfica, por meio do estudo de livros, artigos, dissertações e teses, além de pesquisa documental, com o exame da legislação pertinente, realizando-se, então, uma análise teórica e interpretativa do tema-problema destacado. Obviamente, foram consideradas as regra sobre extensão do artigo, estipulados pelo edital do congresso (essa frase é necessária?).

\section{AS TRANSAÇÕES ADMINISTRATIVAS}

É fato notório que a administração pública não pode, pelo menos a princípio, realizar acordos com seus administrados sem que exista uma norma anterior que dê as diretrizes para tal fim. No plano tributário, porém, dado o enorme volume de ações judiciais, a busca por soluções consensuais não deve ser descartada, apresentando-se como alternativa jurídica plausível para reduzir o número de litígios tributários. Como já observado, o relatório "Justiça em Números" (CNJ, 2020) informa que os processos executivos fiscais representam, aproximadamente, $39 \%$ (trinta e nove por cento) do total de casos pendentes e $70 \%$ (setenta por cento) das execuções inconclusas no Poder Judiciário. Indibutavelmente, é possível afirmar que as causas de natureza tributária contribuem decisivamente para o congestionamento do sistema judiciário. A cultura jurídica de tratamento dos conflitos que 
envolvem o Estado deve ser alterada, e a mudança exige a modificação na própria compreensão do Direito Administrativo.

A resistência em relação às soluções consensuais, em grande medida, decorre de concepção própria dos primórdios do Estado Liberal, que preconizava ser a atuação da Administração pautada pela estrita aplicação da lei, de modo que não haveria espaço para atuação a partir do acordo de vontade. Somente a estrita aplicação legal garantiria a igualdade no agir da Administração Pública, sendo forma de proteção do próprio cidadão. Nesse sentido, Binenbojn afirma que:

A origem liberal e garantistica do direito administrativo, baseada em uma milagrosa submissão da burocracia estatal à lei e aos direitos fundamentais, não passa de um mito. Na verdade, o nascedouro da dogmática administrativa estava comprometido com a preservação do princípio da autoridade e não com a promoção das conquistas democráticas. O objetivo original do direito administrativo era a autovinculação do Poder Executivo à sua própria vontade. (BINENBOJN, 2007, p. 743).

Para Peixoto, o Estado Democrático de Direito passava longe da concepção tradicional do Direito Administrativo, pois, este último visava a "diminuição das garantias que teriam os cidadãos caso pudessem submeter o controle da atividade administrativa ao Poder Judiciário”. (PEIXOTO, 2016, p. 349). Nessa esteira, o Direito Administrativo, em sua concepção clássica, está baseado na ideia de autoridade, ponto de vista que não é o mais adequado no paradigma do Estado Democrático de Direito. Para esse entendimento tradicional, o cidadão está submetido ao poder de império estatal, não havendo, obviamente, espaço para a atuação dialógica ou concertada, devendo a Administração Pública atuar de modo unilateral, preservando sua incontrastável autoridade. Neste modelo, a linha tênue que separa o poder público e o particular é assimétrica, razão pela qual não há espaço para o diálogo coordenado entre eles.

Essa falta de interação estrutural entre Administração Pública e cidadão repercute no Direito Público, em geral, e no Direito Tributário, em particular, alcançando a seara processual. Ocorre que, no processo judicial democrático, ou seja, no processo, num Estado Democrático de Direito, a decisão deve ser construída a partir do diálogo entre as partes, não devendo configurar como imposição da vontade do julgador (DIAS, 2018, p. 44), o que está positivado no princípio da cooperação entre as partes, consagrado no CPC/2015. A participação do cidadão (e a transação tributária não deixa de ser um meio para concretizar a sua participação), em atuação concertada com a Administração, faz com que esse indivíduo 
deixe de ser mero espectador, passando a elaborar, em conjunto com o ente estatal, a solução concomitante para as questões de Direito Público.

Os resquícios do autoritarismo na Administração Pública brasileira são extremamente danosos ao Estado Democrático de Direito. Para chegar a esses apontamentos, é impossível não levar em consideração o fato de que, na maior parte de sua história enquanto Nação, o Brasil não "viveu" diante de ares democráticos, sendo a autocracia a regra. Ainda se somam a esse déficit de experiência democrática males como o patrimonialismo, que seguem gerando distorções no agir da Administração Pública. Como anota Lopes Filho:

O Direito Administrativo clássico prescreve uma concepção francesa de Administração Pública de origem napoleônica e inspiração militar rigidamente hierarquizada e piramidal, a qual influencia a relação interna entre seus integrantes que também se pauta em laços de subordinação. Tanto é assim que um dos mais reconhecidos princípios constitucionais da Administração Pública é o da hierarquia. Também a relação entre cidadão e Administração Pública é tocada por uma perspectiva de hierarquia veladamente confessada nos livros de Direito Administrativo pelo recorrente uso da expressão "administrado" para designar o particular ainda que detentor de direitos. Esse ato falho denota uma implícita perspectiva de uma autoritária relação de ascendência do Poder Público sobre os indivíduos, bem caracterizada pela previsão de prerrogativas do regime jurídico administrativo, que se diferencia daquele de "direito comum". (LOPES FILHO, 2010, s/p.).

A transação administrativa mostra-se como instrumento capaz de atenuar essa lógica unilateral, sendo pertinente colacionar a lição de Batista Júnior, a partir da experiência alemã:

\begin{abstract}
A forma de atuação mais típica e usual é o ato administrativo, entretanto a Administração Pública pode optar por estabelecer, no caso concreto, uma regulação consensual e celebrar com o administrado um contrato. $\mathrm{O}$ contrato administrativo alternativo é uma forma de a Administração Pública resolver determinados casos concretos, como alternativa a uma atuação unilateral, colocando-se como possível mecanismo (mais democrático) para a persecução otimizada do melhor interesse público possível. (BATISTA JÚNIOR, 2007, p. 325).
\end{abstract}

A solução consensual, registra novamente o autor supramencionado, justifica-se também sob a égide da "maior eficiência da atuação administrativa" (BATISTA JÚNIOR, 2007, p.), de modo que Administração e administrado consigam resolver de forma mais eficiente, com menores custos, os litígios eventualmente existente entre eles.

Não é novidade, portanto, o manejo dos contratos administrativos alternativos, fazendo com que a Administração Pública deixe de utilizar, como única maneira de atuação, a conduta impositiva e litigiosa. E, mais uma vez, conforme Batista Júnior (2007, p. 385), a 
"prática do Direito Administrativo Tributário Alemão aceita claramente as transações administrativo-tributário no que diz respeito a questões fáticas, em momento que antecede ao ato final do lançamento".

É importante, assim, que o Direito Administrativo contemporâneo avance para além das bases unilaterais e autoritárias em que foi desenvolvido, devendo ser reescrito em diversos aspectos, porque é cada vez mais ultrapassada a ideia de uma Administração Pública soberana e cuja ação seja sempre pautada por atos unilaterais, desconectados da sociedade civil, que assume papel meramene passivo.

Esse movimento em direção a soluções negociadas vem se tornando cada vez mais forte, podendo ser citada a Lei $n^{\circ} 13.129$, de 2015, que autorizou a Administração Pública a se valer do instituto da arbitragem para resolver conflitos sobre direitos patrimoniais disponíveis. O próprio CPC/2015 trouxe regras que privilegiam, igualmente, a composição no âmbito da própria Administração Pública, como se observa no art. 174, que determina a criação de câmaras de mediação e conciliação, com atribuições para dirimir conflitos na seara administrativa, o que será objeto de outras considerações no tópico subsequente. Por ora, ressalta-se que, a adoção de métodos consensuais para resolver litígios necessita do empenho de todos sujeitos processuais, sendo eles as partes, juízes, membros do Ministério Público, advogados, defensores públicos, e além disso, configura-se como meta a ser buscada, não apenas no Direito Privado, mas também no Direito Público.

Argumentos de cunho filosófico, do mesmo modo, podem ser lembrados, na busca pela melhor compreensão da solução consensual para as controvérsias jurídicas. A inovação teórica introduzida pela dialética hegeliana está no entendimento de que o conflito entre os opostos - tese e antítese - não é ideal, mas real, "tanto no plano de sua efetividade quanto no de sua racionalidade, pois o real e o racional se confundem", como leciona Mascaro (2002, p. 78).

Dessa maneira, o uso da transação no Direito Público, ainda que realizada com terminologias diversas (termos de ajustamento de conduta, termos de ajustamento de gestão, entre outors), tem se tornado uma realidade cada vez mais concreta.

Observe-se que, no Direito Privado, a transação é contrato por meio do qual se previnem ou se terminam litígios, mediante concessões mútuas (art. 840 do Código Civil Lei $\mathrm{n}^{\circ}$ 10.402, de 10 de janeiro de 2002). Teoricamente, igualmente no Direito Público, poderse-ia usar a transação para terminar ou previnir litígio, mas, especificamente no âmbito 
tributário, o CTN limita a transação à terminação do litígio, negando-lhe função preventiva (art. 171).

O instituto da transação, em suma, é forma de solução de controvérsias mediante concessões recíprocas, sendo de se pontuar que o encerramento do litígio, por si só, já é o início de concessões, sendo até muito relevante. Assim, pode-se afirmar que, no ordenamento jurídico pátrio, a solução de controvérsias por meio das transações deve ser também adotada, exigindo-se a mudança do paradigma de soluções de litígios, porque a resolução pela via dos processos judiciais, além de se mostrar ineficiente, dadas as altas taxas de congestionamento, não deve ser a única forma de pacificação, admitindo-se igualmente a transação, a mediação e a conciliação como meios alternativos. No próximo tópico, será abordada, mais especificamente, a transação tributária, como disciplinada na recente Lei no 13.988 , de 2020.

\section{TRANSAÇÃO TRIBUTÁRIA NOS TERMOS DA LEI Nº 13.988, DE 2020}

$\mathrm{Na}$ esteira das exigências do Estado Democrático de Direito, que exige uma Administração Pública mais eficiente e democrática, o Direito Administrativo vai ao encontro da consecução na revisão de vários conceitos forjados sob a concepção de um Estado de Direito ainda pautado pela ênfase no poder de império, na atuação unilateral, privilegiando o ato administrtivo como expressão máxima e única do agir estatal. Em diversas áreas, há sinais recentes de mudanças legislativas, tão esperadas, a fim de que se atinja uma forma de atuação da Administração Pública consensual mais democrática. Há que se reconhecer a possibilidade de celebração de "contratos administrativos (alternativos)", conquanto não se descarte, para sempre, a atuação de modo unilateral, tradicional, por meio do ato administrativo, quando as normas jurídicas impuserem a forma de ato administrativo para a produção dos efeitos de direito, ou a solução consensual não for recomendável.

No Direito Tributário, muito embora já exista a previsão no art. 171 do CTN da viabilidade de se realizar a transação tributária mediante concessões recíprocas entre os sujeitos ativo e passivo da obrigação tributária, a efetivação dessa possibilidade dependia da edição de lei específica em cada ente tributante. 
Nesse sentido, no plano federal, o Congresso Nacional aprovou a mencionada Lei $\mathrm{n}^{\circ}$ 13.98, de 2020, que chegou em boa hora para suprir a lacuna normativa até então existente, de modo a retirar o assunto do plano teórico.

A edição da Lei de Transação Tributária relaciona-se com as mudanças que vêm sendo realizadas, sendo de se destacar que também o CPC/2015 trouxe nova leitura sobre a realidade processual brasileira, em especial, com o estabelecimento dos princípios da cooperação e da consensualidade, sendo estes alguns dos pilares do referido código.

Também é de se registrar a promulgação da Lei n 13.140 , de 2015, que dispõe sobre a mediação entre particulares como meio de solução de controvérsias, estabelecendo, do mesmo modo, sobre a autocomposição de conflitos no contexto da Administração Pública, possibilitando, inclusive, a criação de câmaras de prevenção e resolução administrativa de conflitos no âmbito da União, Estados, Distrito Federal e Municípios.

Para o sistema jurídico como um todo, não é mais novidade a existência de formas alternativas de resolução de conflitos, ao passo que é até mesmo obsoleto tratar tais modalidades enquanto alternativas, uma vez que muitas delas já foram incorporadas pelo sistema judiciário como, por exemplo, a Mediação, Conciliação e a Arbitragem.

Essa nova opção feita pelo legislador resultou da grave crise de efetividade pela qual passava e continua a passar a jurisdição brasileira, resultado de uma cultura de litigiosidade no mais alto grau. O legislador percebeu a necessidade de normas também voltadas à consensualidade. Malgrado o acesso à justiça seja direito fundamental, a incapacidade de o Poder Judiciário atuar de forma efetiva e em tempo razoável conduzia ao desgaste e descrédito do próprio Judiciário. Daí, pois, a iniciativa da Procuradoria Geral da Fazenda Nacional (PGFN), que editou normas infralegais disciplinando a realização de transações tributárias, como, por exemplo, a Portaria PGFN no 396, de 20 de abril de 2016, e a Portaria PGFN $n^{\circ} 33$, de 8 de fevereiro de 2018. Tais normas trouxeram, em seu bojo, manifestações do anseio de ruptura com o ambiente de excessiva litigiosidade tributária.

É claro que não basta criar leis para se institucionalizar um modelo de solução de disputas com destaque para o consenso, sendo necessária verdadeira mudança de paradigma da cultura jurídica de excessiva judicialização dos conflitos, principalmente em torno de relações jurídicas com o Poder Público. Se não se combater essa tradição ou esse paradigma da lide contenciosa no Brasil, provavelmente serão minimizados os eventuais impactos 
positivos advindos do emprego de instrumentos negociais, consensuais e extrajudiciais criados pelo legislador para resolução de controvérsias.

Dessa forma, a solução de conflitos por meios consensuais deve expressar mesmo uma política pública de interesse coletivo. É necessário estimular a autocomposição das controvérsias para que a almejada pacificação social seja obtida sem a necessidade do Judiciário. Carnelutti (2000, p. 62-63) aponta que:

\begin{abstract}
A medida em que a civilização progride, há menos necessidade do Direito para atuar com a solução pacífica do conflito, não apenas porque cresce a moralidade, como também, mais que tudo, porque aumenta a sensibilidade dos homens perante supremo interesse coletivo.
\end{abstract}

Portanto, além das legislações que autorizam a transação tributária, torna-se imprescindível a mudança de postura e, por assim dizer, o amadurecimento da sociedade em relação à cultura do litígio.

A possibilidade de solução consensual, nos termos da Lei $n^{\circ} 13.988 / 2020$, pode abranger créditos tributários inscritos em dívida ativa da União, cujo conflito decorra basicamente da situação de inadimplemento ocasionado pelo não pagamento voluntário do valor considerado devido ao fisco, não havendo litígio jurídico sério em torno da legitimidade do crédito tributário. Mas também podem ser incluídos créditos tributários contenciosos, isto é, objeto de controvérsia jurídica séria, com o risco de reconhecimento de sua ilegalidade ou inconstitucionalidade. Dessa maneira, a transação tributária poderá envolver créditos tributários contenciosos e não contenciosos.

Assim, identificados os créditos passíveis de transação, emergem as opções disponíveis ao sujeito passivo para que ele possa extinguir, ou ao menos reorganizar, seu passivo fiscal. Nesse esteira, a legislação trouxe a possibilidade do próprio contribuinte ou a própria Fazenda Nacional apresentar proposta individual de resolução de litígios, sendo tal proposta restrita aos chamados créditos não contenciosos (art. $2^{\circ}$ da Lei $n^{\circ} 13.988 / 2020$ ).

É importante observar que, na modalidade individual, muito embora o acordo seja feito de modo particular, este fato, por si só, não permite que o princípio da isonomia seja deixado à margem, pois haveria ameaça à própria concorrência econômica entre os contribuintes. Entretanto, como existem critérios objetivos e subjetivos a serem observados pela Procuradoria Geral da Fazenda Nacional, o princípio da isonomia somente irá ser afetado 
se nas mesmas condições de valores do crédito tributário, prazo de ações em curso, tipo de tributo forem análogos (art. $2^{\circ}$, art. $3^{\circ}$, art. 11, § $2^{\circ}$, entre outros, da Lei ${ }^{\circ} 13.988 / 2020$ ).

Ademais, aspecto novo que deve ser ressaltado e foi instituído pela legislação é, além da previsão de aplicação de descontos dos acessórios, juros, multas e encargo legal, a possibilidade de desconto do valor principal da obrigação tributária naqueles casos em que o Poder Judiciário já decidiu contrariamente aos anseios da Fazenda Pública (art. 11, inciso I e $\S$ $2^{\text {o }}$ da Lei $\left.n^{\text {o }} 13.988 / 2020\right)$.

Continuando na análise do texto legal, percebe-se que esse ponto supracitado não é o único atrativo do instituto da transação tributária, pois também existem condições de prazos alongados para satisfação do crédito tributário, com a opção de diferimento e até mesmo moratória, que, em conjunto com os descontos, podem viabilizar positivamente a situação fiscal do contribuinte (art. 11, inciso II da Lei $n^{\circ}$ 13.988/2020). Atinente a essa questão, dúvidas não pairam a respeito de que, em relação àquele contribuinte que pretende regularizar sua situação perante a Fazenda Nacional, a nova legislação evidentemente permite o oferecimento de vantagens consideráveis, capazes de estimular a opção pelo encerramento do litígio. Lado outro, o contribuinte que se caracteriza como devedor contumaz encontrará vários obstáculos e impedimentos para a obtenção dos benefícios legais, ao contrário do que ocorre nos reiterados regimes de parcelamento alongados, objeto de sérias críticas pelo estímulo que dão à permanência da inadimplência. (MUZZI FILHO; GONÇALVES, QUADROS, 2018).

Sobre o devedor contumaz, a inserção do art. 5 , inciso III da Lei n ${ }^{\circ}$ 13.988/2020 ocorreu por iniciativa de emendas parlamentares. A introdução da redação atual do dispositivo ocorreu com a aprovação do parecer da Comissão Mista do Congresso Nacional, no qual se ressaltou inexistir definição legal do que seja devedor contumaz, reputando o tema complexo para ser revolvido em exíguo período. A vedação do devedor contumaz para realização de transações tributárias ocorreu porque sua figura é associada ao contribuinte que, de modo intencional e reiterado, deixa de adimplir com as suas obrigações tributárias, apesar de possuir capacidade de pagamento, com o objetivo de se financiar por via oblíqua com o dinheiro público. (BOEING, 2020).

Em contraponto às emendas parlamentares, ao comentar a Medida Provisória ${ }^{\circ} 899$, de 2019, posteriormente convertida na Lei $n^{\circ} 13.988$, de 2020, Machado Segundo (2019) se posicionou favoravelmente à teleologia da regra do art. $5^{\circ}, \S 2^{\circ}$, inciso II da MP, ponderando 
que, em programas de parcelamentos anteriores, a ausência da referida disposição torna "mais atrativos quanto mais graves fossem as irregularidades cometidas pelo contribuinte".

Existe ainda, no texto legal, a viabilidade de a negociação envolver as garantias que dão lastro à dívida, para fins de conferir maior segurança ao credor de que aquela transação será cumprida e os valores irão para os cofres públicos (art. 11, incis III da Lei $\mathrm{n}^{\circ}$ $13.988 / 2020)$.

Portanto, sinteticamente, pode-se afirmar que o legislador optou por duas modalidades de transação tributária: por proposta individual, conforme art. $2^{\circ}$, inciso I da Lei $\mathrm{n}^{\circ}$ 13.988/2020, sendo aquela oferecida pelo particular em relação a créditos tributários contenciosos; por adesão, nos termos do art. $2^{\circ}$, incisos II e III da Lei ${ }^{\circ}$ 13.988/2020, a partir de conteúdo já estipulado pela Fazenda Nacional relativamente aos créditos tributários não contenciosos.

Do mesmo modo é possível explorar, dentro dessa análise, o caso de repercussão nacional de transação tributária individual, que ocorreu entre o Cruzeiro Esporte Clube e a Fazenda Nacional. A PGFN e o clube em questão celebraram acordo de transação, o qual permitiu ao clube de futebol renegociar débitos tributários no valor total de $\mathrm{R} \$ 334$ (trezentos e trintta e quatro) milhões de reais, incluindo débitos de natureza no valor previdenciária, inscritos na dívida ativa da União. O acordo foi formalizado por meio da modalidade de transação individual, para equacionar um passivo de quase R\$ 328 (trezentos e vinte e oito) milhões de reais, que serão pagos com descontos sobre o valor dos encargos (R 150 milhões). O montante negociado será pago em 60 (sessenta) parcelas mensais, no caso das dívidas previdenciárias, e em 145 (cento e quarenta e cinco) parcelas, para os demais débitos ${ }^{1}$.

O Supremo Tribunal Federal (STF), em decisão monocrática, já teve a oportunidade de invocar a Lei no 13.988/2020, ressaltando a importância de se buscar o "equacionamento da dívida tributária":

[...] Mais recentemente também é possível vislumbrar, em âmbito federal, a expedição da Certidão de Regularidade Fiscal ao devedor que realiza a transação tributária com o Fisco nos termos da novel Lei 13.988/2020.

[...] Em artigo publicado no jornal Valor Econômico, esse caráter sinalagmático da transação tributária como elemento para a regularização dos débitos fiscais,

\footnotetext{
${ }^{1}$ Informações disponíveis no site da Procuradoria-Geral da Fazenda Nacional: "PGFN e Cruzeiro Esporte Clube formalizam acordo de transação no valor de R 334 milhões - Lei do Contribuinte Legal permitiu ao clube de futebol mineiro regularizar passivo tributário". Disponível em: https://www.gov.br/pgfn/ptbr/assuntos/noticias/pgfn-e-cruzeiro-esporte-clube-formalizam-acordo-de-transacao-no-valor-de-r-334-milhoes.
} 
desejável em qualquer processo de recuperação judicial, foi bem destacado por Gabriel Augusto Luís Teixeira e Daniele de Lucena Zanforlin:

[...] Esse novo contexto vem a confirmar o papel crucial do equacionamento da dívida tributária para a efetiva recuperação da atividade econômica, a qual não se verifica se deixar como resultado do benefício judicial um passivo milionário com o Estado e a sociedade. Nesse sentido, não busca o Fisco e a PGFN o mero incremento da arrecadação tributária, mas uma participação efetiva e positiva no soerguimento da atividade empresarial, entendendo as dificuldades inerentes ao ciclo econômico, como é exemplo a regulamentação da transação extraordinária e a transação excepcional, com procedimento de adesão simplificado e rápido e disposições que visam auxiliar a recuperação das empresas afetadas por essa crise decorrente da pandemia da COVID-19. (STF - MC Rcl 0102138-58.2020.1.00.0000 SP, Rel. Min Luiz Fux, DJE 09/09/2020).

Constata-se, então, que a transação tributária já vai se tornando realidade na prática tributária, com inegável impulso provocado pela Lei nº 13.988 , de 2020, seja na modalidade individual, seja na modalidade por adesão. Ainda é cedo, contudo, para se poder fazer avaliação completa sobre o sucesso, ou não, do emprego desse instituto.

\section{A TRANSAÇÃo TRIBUTÁRIA COMO FORMA DE DESAFOGAR O PODER JUDICIÁRIO}

A transação tributária configura-se na forma de concessões mútuas por ambas as partes, com o objetivo de suspender ou extinguir a obrigação tributária e, com vistas à efetividade da cobrança, à economicidade da operação, à composição de conflitos e à terminação de litígios judiciais.

Para a Administração Pública, em análise simplória, poder-se-ia dizer que a redução dos valores exigidos configuraria excessiva concessão, mas se a interpretação é complementada pelo exame da maior ou menor probabilidade de satisfação da dívida tributária, bem como maior celeridade no efetivo recebimento do crédito tributário (ainda que em montante inferior), torna-se plausível o reconhecimento de paridade nas concessões feitas pelas partes.

Lembra Moraes (1994, p. 456-458) que, na transação, deve estar presente algum grau de incerteza no direito objeto de discussão para que seja viável a existência de concessões recíprocas entre o sujeito ativo e passivo da relação jurídica tributária, a fim de por fim ao litígio, e a incerteza pode estar, ainda, no "receio do resultado de um processo ainda não iniciado", dúvida essa que pode decorrer da insolvabilidade do sujeito passivo: 
É inerente, na transação, haver ônus e vantagens recíprocas diante de um litígio ou de uma controvérsia. Um dos elementos essenciais da transação é a existência de uma relação jurídica duvidosa, a res dubia, ou melhor, a incerteza nas pretensões das partes [...] Tornam-se essenciais na transação essa controvérsia e essa reciprocidade no conceder. [...] A transação exige a existência de uma relação jurídica duvidosa, mesmo que seja o receio do resultado de um processo ainda não iniciado, e a existência de concessões mútuas, de parte a parte. (MORAES, 1994, p. 456-458).

A transação, ademais, deve ser considerada uma evolução em relação ao parcelamento, quer o parcelamento comum, quer o chamado parcelamento especial, pois, acrescenta a análise da viabilidade do recebimento do crédito, seja em razão da solvabilidade do sujeito passivo, seja em razão do grau de certeza jurídica deste crédito tributário. E o seu papel na redução do número de ações judiciais se anuncia bem mais importante, dada a reiteração de parcelamentos especiais, a apontar para a incapacidade desses mecanismos para resolver os litígios, mas, ao contrário, perpetuá-los. (MUZZI FILHO; GONÇALVES; QUADROS, 2018).

Nesse contexto, experiência exitosa se tem no município de Blumenau, Estado de Santa Catarina, onde foi editada a Lei Municipal $n^{\circ}$ 8.532, de 2017, que igualmente dispôs sobre a transação de créditos tributários e não tributários, bem como criou a câmara de transação tributária, obviamente em relação aos tributos municipais. A aplicação da transação, no contexto municipal, possui resultado em expressiva redução do volume de processos de execução fiscal, acompanhado de igualmente expressivo incremento na arrecadação. (POMPERMAIER; FARIAS; AMARAL E SILVA, 2020).

O modelo de câmaras de transação para a composição do litígio tributário pode ser relevante mecanismo para a transformação do processo de trabalho das advocacias públicas, contribuindo significativamente para o avanço na diminuição de novas execuções fiscais. Como já apontado, não basta apenas a criação de leis para autorizar a transação tributária, pois o comportamento altamente litigioso comumente praticado pelos diversos entes e entidades que compõem a Administração Pública brasileira não se mostra condizente com a ideia de uma Administração Pública consensual, que atua em prol do cidadão. A consolidação de uma cultura jurídica que perpetua o poder público na condição de maior litigante habitual do sistema jurídico pátrio, como citado nos relatórios do Conselho Nacional de Justiça, acarreta consequências nefastas não somente no adequado funcionamento do sistema jurídico de resolução de disputas, mas também cria obstáculos quase intransponíveis à materialização 
efetiva e célere de direitos e garantias constitucionais básicos de particulares na esfera extrajudicial. Nesse tom, Santos observa:

No preâmbulo da Constituição, há a nominação da justiça como valor supremo de
uma sociedade fraterna, pluralista e sem preconceitos. E, neste caso, como defendido
ao longo do trabalho, o alcance da justiça enquanto valor não se dá apenas com o
acesso simplório à clássica noção de tutela jurisdicional, mas, sim, com a mais
ampla possibilidade de pacificação de conflitos, notadamente num sistema
multiportas, que dá acesso à caminhos, à métodos de solução de conflitos que se
coadunam com os valores e princípios previstos em nosso ordenamento. (SANTOS,
2020).

É incompatível com o Estado Democrático de Direito que a Administração Pública, como "braço" do Estado, adote sempre uma postura de enfrentamento, uma postura belicosa, que concorra para a manutenção e o agravamento do estado de crise do judiciário, como outro ramo do Estado. Não deve a Administração Pública utilizar o processo judicial de forma desvirtuada, como se fosse um meio de litigiosidade voltado exclusivamente para a protelação de cumprimento das obrigações impostas ao Poder Público (DUTRA, 2016). Assim, relevante papel se impõe à advocacia pública na transformação da cultura do litígio para a cultura do consenso.

Nesse paradigma, de acordo com Binenbojn (2011, p. 220), é cabível identificar dois tipos de compromissos constitucionais inerentes à atuação da advocacia pública, a saber: a) um compromisso democrático, consistente na viabilização, no plano jurídico, das politicas públicas definidas pelos agentes políticos eleitos; b) um "compromisso jurídico, consubstanciado no ajuste e na conformação dos atos dos agentes políticos eleitos e dos gestores administrativos ao quadro de limites e possibilidades estabelecidos pelo ordenamento jurídico".

Então, o aprimoramento do modelo de tratamento dos conflitos tributários, por meio das transações tributárias, deve ser buscado pelos gestores públicos, a fim de que se conquiste a integração harmônica entre as atividades de viabilização de políticas públicas e da prevenção de conflitos desnecessários, com o fito de evitar a propositura de ações judiciais desnecessárias.

Atinente a essa questão, cabe ressaltar fatores importantes em relação ao papel do Direito Tributário para o Estado. É óbvio que os tributos possuem múltiplas funções para o Estado e para a sociedade, todavia, a sua função prioritária é a fiscal, uma vez que os tributos financiam o ente estatal. Assinala Oliveira (2013) que, "por meio da instituição de tributos, 
uma parcela da riqueza do particular é transferida ao Poder Público, para a realização de seus fins, no atendimento das necessidades coletivas". Nesse sentido, todas as ações que tornem possível a satisfação dos créditos tributários do Estado são bem vistas, afinal, muitos créditos tributários que não seriam satisfeitos pela via judicial (ou extintos por força de prescrição), podem ter um destino diferente, com sua satisfação, ainda que parcial (em razão das concessões mútuas), mediante alternativas ao litígio no processo.

Portanto, constatam-se múltiplos argumentos que demonstram de que forma a transação tributária pode ser ultilizada como via de satisfação dos créditos tributários, de um modo mais eficaz e menos oneroso tanto para o Estado, quanto para os particulares, bem como também se mostra como uma maneira de se efetivar uma postura da administração pública mais contemporaneizada e submissa aos ditames do Estado Democrático de Direito, portanto, distante de resquícios autoritários que se fazem presentes, até hoje, em sua atuação leonina. Além disso, evidencia-se sua eficácia, por tabela (eu tiraria esse termo...), em desafogar o sistema judiário, uma vez que dados supracitados, reitera-se, aqui, novamente, demonstram que a maior parte das açõs judiciais em curso e de matéria não penal tratam-se de execuções fiscais da dívida ativa.

No Direito Privado, já é evidente e possível de se observar, em números concretos, de que maneira métodos alternativos ao processo judicial foram capazes de diminuir a litigância judicial e tornar a satisfação das demandas mais célere, conforme relatório do CNJ, de 2019, que informa o fato de que "processos solucionados via conciliação e mediação tendem a ter menor quantidade de movimentação processual e duram a metade do tempo que os processos não conciliados" (CNJ, 2019). Igualmente necessário que, levando-se em consideração os apontamentos feitos, torna-se imprescindível enfrentar o desafio da aplicação desses institutos também no Direito Público e, nessa toada, a transação tributária surge, portanto, como um meio de desafogar o Poder Judiciário.

\section{CONCLUSÃO}

Neste artigo foi possível constatar que a atual forma em que se dá a relação jurídica entre particulares e a Administração Pública deve ser aprimorada para privilegiar o consenso entre as partes. Essa releitura do direito tributário pressupõe a formatação de novos pilares 
baseados nas noções de participação, flexibilidade e consensualidade, a fim de que modificações substanciais, apontadas ao decorrer do texto, possam ser realizadas.

A abertura para a democratização do direito tributário-administrativo e a possibilidade de se atingir uma maior satisfação dos princípios do Estado Democrático de Direito ultrapassam o excesso de rigores e de formalidades outrora existentes na busca por uma compreensão do direito tributário voltado para a Constituição.

Não apenas a satisfação desses princípios é um fator que sustenta essa tese, mas também a realidade morosa e a lentidão do sistema judiciário, que se configura como outro fundamento para tal, vez que traz efeitos nefastos para toda a sociedade. $O$ cenário de congestionamento do Poder Judiciário exige dos gestores públicos uma mudança de postura em relação aos procedimentos até então adotados antes do ajuizamento das execuções fiscais. Todavia, também foi apontado que tais modificações sugeridas exigem uma alteração legislativa, que hoje se dá de forma incipiente, necessitando ser intensificada, conjulgada a, principalmente, uma mudança de cultura dos gestores públicos.

Nesse contexto, o que esses apontamentos demonstram é que somente a institucionalização da transação tributária enquanto legislação, por si só, não é suficiente para tais modificações. Aliado a isso, deve haver uma mudança de postura também da gestão das procuradorias públicas, que são as responsáveis por representar os entes públicos perante os processos judiciais, bem como desestímulos à cultura de litígio. Em relação à advocacia pública, inclusive, ressalta-se a transformação no modo de trabalho em relação à condução do processo, deixando de lado a velha prática de recorrer até às últimas instâncias judiciais em matérias já decididas reiteradas vezes pelos tribunais, fato que apenas torna o Judiciário mais moroso e congestionado.

Isso posto, o Estado deve, sempre que possível, dar a oportunidade ao particular para poder resolver o crédito tributário antes do ajuizamento das execuções fiscais, e, durante o curso dos processos, privilegiar a composição com a participação ativa dos Juízes.

É nessa esteira que o aprimoramento da gestão do Poder Judiciário deve empregar meios que levem à redução do ingresso de novas execuções fiscais, mantendo, permanentemente, o necessário equilíbrio entre a recuperação eficiente do crédito tributário e a diminuição dos custos com a manutenção dessas ações pelas instituições jurídicas.

Assim sendo, a transação tributária se mostra como instrumento à disposição dos sujeitos da relação jurídico-tributária, inaugurando uma nova fase do sistema de solução de 
litígios. A adoção de métodos extrajudiciais de resolução de conflitos administrativos se mostra como tendência irreversível. Este cenário, além do escopo de produzir uma solução mais adequada de acordo com as particularidades do caso concreto, o emprego de técnicas “desjudicializadas", possui o condão de imprimir maior eficiência à própria atividade jurisdicional.

Dentro desse contexto, a Lei $\mathrm{n}^{\circ}$ 13.988/2020 trouxe duas formas de transação tributária no âmbito federal, sendo elas por adesão e a individual. A primeira traz, de forma antecipada, as regras para aceitação da transação e a segunda possibilita a definição das regras posteriormente às tratativas com a Procuradoria Geral da Fazenda Nacional.

Assim, dúvidas não restam que devem ser reconhecidas como avanços as novas legislações que regulamentaram as transações tributárias, sejam elas na seara Federal, Estadual ou Municipal, e tantas outras possam surgir para viabilizar as transações tributárias com vistas a reduzir o número de ações executivas fiscais em trâmite perante o Poder Judiciário. Tese essa, sustentada por fundamentos muito importantes para a efetivação do Estado Democrático de Direito, bem como relevantes também do ponto de vista fiscal, primeira preocupação do Direito Tributário, uma vez que a mesma, conforme demonstrado, gera menor onerosidade ao Estado.

\section{REFERÊNCIAS}

BATISTA JUNIOR, Onofre Alves. Transações Administrativas: um contributo ao estudo do contrato administrativo como mecanismo de prevenção e terminação de litígios e como alternativa à atuação administrativa, no contesto de uma administração pública mais democrática. São Paulo: Quartier Latim, 2007.

BINENBOJM, Gustavo. A Constitucionalização do Direito Administrativo no Brasil: um inventário de avanções e retrocessos. In: SOUZA NETO, Claudio Pereira de; SARMENTO, Daniel (coord). A constitucionalização do Direito: Fundamentos teóricos e aplicações especificas. Rio de Janeiro: Lumen Juris, 2007. 
BINENBOJM, Gustavo. A Advocacia e o estado Democrático de Direito. Revista da Procuradoria Geral do Município de Juiz de Fora. Belo Horizonte, ano 1, n.1, jan./dez. 2011.

BOEING, Ana Paula Sabetzki. Enfim, uma esperança para a transação tributária: uma breve análise da Lei n. 13.988/2020. Direito do Estado em Debate, 28 set. de 2020.

BRASIL. Lei $\mathbf{n}^{0}$ 5.172, de 25 de outubro de 1966. Institui o Código Tributário Nacional. Disponível em: http://www.planalto.gov.br/ccivil_03/leis/15172compilado.htm. Acesso em: 6 jan. 2021.

BRASIL. Lei $\mathbf{n}^{\mathbf{0}}$ 10.402, de 10 de janeiro de 2002. Institui o Código Civil. Disponivel em: https://www2.camara.leg.br/legin/fed/lei/2002/lei-10406-10-janeiro-2002-432893-

publicacaooriginal1pl.html\#: :text=Art.,concep\%C3\%A7\%C3\%A3o\%2C\%20os\%20direitos \%20do\%20nascituro. Acesso em:6 jan. 2021.

BRASIL. Lei $\mathbf{n}^{0}$ 13.105, de 16 de março de 2015. Instituiu o Código de Processo Civil. Disponível em: http://www.planalto.gov.br/ccivil_03/_ato2015-2018/2015/lei/113105.htm. Acesso em: 6 jan. 2021.

BRASIL. Lei $\mathbf{n}^{\mathbf{0}}$ 13.129, de 26 de maio de 2015. Altera a Lei $\mathrm{n}^{\circ}$ 9.307, de 23 de setembro de 1996, e a Lei ${ }^{\circ}$ 6.404, de 15 de dezembro de 1976, para ampliar o âmbito de aplicação da arbitragem e dispor sobre a escolha dos árbitros quando as partes recorrem a órgão arbitral, a interrupção da prescrição pela instituição da arbitragem, a concessão de tutelas cautelares e de urgência nos casos de arbitragem, a carta arbitral e a sentença arbitral, e revoga dispositivos da Lei $\mathrm{n}^{\mathrm{o}}$ 9.307, de 23 de setembro de 1996. Disponível em: https://www2.camara.leg.br/legin/fed/lei/2015/lei-13129-26-maio-2015-780858-normapl.html. Acesso em: 6 jan. 2021.

BRASIL. Lei $\mathbf{n}^{0}$ 13.140, de 26 de junho de 2015. Dispõe sobre a mediação entre particulares como meio de solução de controvérsias e sobre a autocomposição de conflitos no âmbito da administração pública; altera a Lei $n^{\circ} 9.469$, de 10 de julho de 1997 , e o Decreto $\mathrm{n}^{\circ} 70.235$, de 6 de março de 1972; e revoga o $\S 2^{\circ}$ do art. $6^{\circ}$ da Lei $n^{\circ} 9.469$, de 10 de julho de 1997. Disponível em: http://www.planalto.gov.br/ccivil_03/_ato2015-2018/2015/lei/113140.htm. Acesso em: 6 jan. 2021.

BRASIL. Lei $\mathbf{n}^{\mathbf{0}} \mathbf{1 3 . 9 8 8}$, de 14 de abril de 2020. Dispõe sobre a transação nas hipóteses que especifica; e altera as Leis nos 13.464, de 10 de julho de 2017, e 10.522, de 19 de julho de 2002. Disponível em: http://www.planalto.gov.br/ccivil_03/_ato20192022/2020/lei/113988.htm. Acesso em: 6 jan. 2021.

BRASIL. Portaria da Procuradoria Geral Fazenda Nacional $\mathbf{n}^{\circ}$ 396, de 20 de abril de 2016. Regulamenta no âmbito da procuradoria Geral da Fazenda Nacional, o regime diferenciado da cobrança de créditos. Disponível em: https://www.gov.br/pgfn/ptbr/assuntos/divida-ativa-da-uniao/regime-diferenciado-de-cobrancardcc/portaria396_2016_1.pdf. Acesso em: 6 jan. 2021. 
BRASIL. Portaria da Procuradoria Geral Fazenda Nacional $\mathbf{n}^{\mathbf{0}}$ 33, de 08 de fevereiro de 2018. Regulamenta os arts. 20-B e 20-C da Lei $\mathrm{n}^{\circ} 10.522$, de 19 de julho de 2002 e disciplina os procedimentos para o encaminhamento de débitos para fins de inscrição em dívida ativa da União, bem como estabelece os critérios para apresentação de pedidos de revisão de dívida inscrita, para oferta antecipada de bens e direitos à penhora e para o ajuizamento seletivo de execuções fiscais. Disponível em:

http://sijut2.receita.fazenda.gov.br/sijut2consulta/link.action?idAto=90028\&visao=anotado. Acesso em: 6 jan. 2021.

BRASIL. Supremo Tribunal Federal. Medida Cautelar na Reclamação 010213858.2020.1.00.0000/SP. Reclamação. Constitucional. Tributário. Homologação de Recuperação Judicial. Exigência da Certidão de Regularidade Fiscal. Artigo 150, da Lei 11/101/2005. Artigo 191-A do Código Tributário Nacional. Alegação de ofensa à Súmula Vinculante 10. Reclamante: União. Reclamado: Superir Tribunal de Justiça. Relator: Min. Luiz Fux, 9 de setembro de 2020. Disponível em: https://stf.jusbrasil.com.br/jurisprudencia/924590602/medida-cautelar-na-reclamacao-rcl43169-sp-0102138-5820201000000/inteiro-teor-924590692?ref=feed. Acesso em: 6 jan. 2021.

BLUMENAU. Lei $\mathbf{n}^{0}$ 8.532, de 19 de dezembro de 2017. Dispõe sobre transação de créditos tributários e não tributários do Município de Blumenau objeto de execução fiscal ajuizada até 31.12.2014 ou de litigio judicial, nas hipóteses que especifica e dá outras providencias. Disponível em https://www.diariomunicipal.sc.gov.br/site/?r=site/acervoView\&id=1461900. Acesso em: 7 jan. 2021.

CARNELUTTI, Francesco. Sistema de direito processual civil. Tradução de Hiltomar Martins Oliveira. São Paulo: Classic Book. 2000. v. 1.

CONSELHO NACIONAL DE JUSTIÇA. Mediação e conciliação avaliadas empiricamente: jurimetria para proposição de ações eficientes. Brasília, 2019. Disponível em: <https://bibliotecadigital.cnj.jus.br/jspui/handle/123456789/321>. Acesso em: 29 ago. 2021.

CONSELHO NACIONAL DE JUSTIÇA. Justiça em Números. Brasília, 2020. Disponível em: https://www.cnj.jus.br/wp-content/uploads/2020/08/WEB-V3-Justi\%C3\% A7a-emN\%C3\%BAmeros-2020-atualizado-em-25-08-2020.pdf. Acesso em: 6 jan. 2021.

DIAS, Ronaldo Brêtas de Carvalho. Processo constitucional democrático e Estado Democrático de Direito. 4 ed. Belo Horizonte: Del Rey, 2018.

DUTRA, Raphael Vasconcelos. O estatuto jurídico dos procuradores e das procuraturas municipais e o necessário aprimoramento constitucional. 2016. Dissertação (Mestrado) Faculdade de Ciências Humanas, Sociais e da Saúde (FUMEC), Belo Horizonte, 2016.

LOPES FILHO, Juraci Mourão. A democracia na administração pública e no direito administrativo brasileiro. Revista Opinião Jurídica. Fortaleza, v. 8, n. 12, 2010. 
MACHADO SEGUNDO, Hugo de Brito. MP do "contribuinte legal" reacende a discussão sobre a transação tributária. Consultor Jurídico, 30 de outubro de 2019. Disponível em: https://www.conjur.com.br/2019-out-30/consultor-tributario-mp-contribuinte-legal-reacendedebate-transacao-tributaria. Acesso em: 6 jan. 2021.

MASCARO, Alysson Leandro. Introdução à Filosofia do Direito - Dos Modernos aos Contemporâneos. São Paulo: Atlas, 2002.

MORAES, Bernardo Ribeiro de. Compêndio de direito tributário. Rio de Janeiro: Forense, 1994, v. II.

MUZZI FILHO, Carlos Victor; GONÇALVES, Antonieta Caetano; QUADROS, Aparecida Dutra de Barros. O princípio da (in)eficiência no controle dos reiterados programas de refinanciamentos de débitos tributários federais ("REFIS"). Revista da Faculdade de Direito do Sul de Minas, Pouso Alegre, v. 34, n. 2, jun./dez. 2018, p. 357-374.

OLIVEIRA, Phelippe Theodoro Pires de. A Transação em Matéria Tributária. 2013. Tese (Mestrado em Direito Econômico e Financeiro) - Faculdade de Direito da Universidade de São Paulo, São Paulo, 2013.

PEIXOTO, Ravi. Primeiras impressões sobre os meios consensuais de resolução de conflitos pelo poder público e as alterações promovidas pelo CPC/2015 e pela Lei 13.140/2015. In: TALAMINI, Eduardo (coord.); DIDIER JUNIOR, Fredie (coord. geral). Processo e Administração Pública. Salvador: Jus Podivm, 2016.

POMPERMAIER, Cleide Regina Furlani; FARIAS, Ângela dos Santos; AMARAL E SILVA, Emanuel Schenkel. Três anos de transação de créditos municipais em Blumenau: um balanço A humanização do processo e a escuta ativa fazem a grande diferença na relação fiscocontribuinte. In: Jota - Pauta Fiscal. Disponível emhttps://www.jota.info/opiniao-eanalise/colunas/pauta-fiscal/transacao-de-creditos-municipais-em-blumenau-um-balanco06112020. Acesso em: 28 set. 2021.

SANTOS, Helder Silva dos. Transação Tributária: Limites, Desafios e Propostas. Tese (Mestrado em Direito Tributário). São Paulo: Escola de Direito de São Paulo, Fundação Getúlio Vargas, 2020. 